\title{
Light at the end of the channel: optical manipulation of intrinsic neuronal excitability with chemical photoswitches
}

\author{
Alexandre Mourot ${ }^{1,2 *}$, Ivan Tochitsky ${ }^{1}$ and Richard H. Kramer ${ }^{1}$ \\ Department of Molecular and Cell Biology, University of California, Berkeley, CA, USA \\ ${ }^{2}$ Department of Neurobiology of Adaptive Processes, UMR7102 CNRS, Université Pierre et Marie Curie, Paris, France
}

\section{Edited by:}

Pau Gorostiza, Institució Catalana de Recerca i Estudis Avançats, Spain

\section{Reviewed by:}

Jean-Philippe R. Pin, Université de Montpellier, France

Can Peng, University of Florida, USA

\section{*Correspondence:}

Alexandre Mourot, Department of Neurobiology of adaptive processes, UMR7102 CNRS, Université Pierre

et Marie Curie, 9 quai St. Bernard, 75005 Paris, France.

e-mail:almourot@gmail.com
Ion channels are transmembrane proteins that control the movement of ions across the cell membrane. They are the molecular machines that make neurons excitable by enabling the initiation and propagation of action potentials (APs). Rapid signaling within and between neurons requires complex molecular processes that couple the sensing of membrane voltage or neurotransmitter release to the fast opening and closing of the ion channel gate. Malfunction of an ion channel's sensing or gating module can have disastrous pathological consequences. However, linking molecular changes to the modulation of neural circuits and ultimately to a physiological or pathological state is not a straightforward task. It requires precise and sophisticated methods of controlling the function of ion channels in their native environment. To address this issue we have developed new photochemical tools that enable the remote control of neuronal ion channels with light. Due to its optical nature, our approach permits the manipulation of the nervous system with high spatial, temporal and molecular precision that will help us understand the link between ion channel function and physiology. In addition, this strategy may also be used in the clinic for the direct treatment of some neuronal disorders.

Keywords: optochemical genetics, optogenetics, chemical genetics, photopharmacology, photoswitches, ion channels, azobenzene

\section{INTRODUCTION}

Light is the ideal external stimulus for controlling biological processes with high accuracy: it can be manipulated with very high spatial and temporal precision, it can be projected onto a tissue from afar and, because cells are typically not intrinsically photosensitive, light can be used as an orthogonal, highly specific stimulus. In the last decade, research in neuroscience has resulted in an explosion of strategies aiming at optically controlling electrical signals, by rendering ion channels and neurons light-sensitive. These approaches include naturally photosensitive proteins and protein domains, caged neurotransmitters and reversible photoswitches (Kramer et al., 2009; Miesenbock, 2011; Brieke et al., 2012). The microbial opsins channelrhodospin, halorhodopsin and archaerhodopsin as well as other light-sensitive ion channels and transporters have revolutionized neuroscience, by enabling the remote control of neuronal excitability (Boyden et al., 2005;

\footnotetext{
Abbreviations: AAQ, acrylamide-azobenzene-quaternary ammonium; AIS, Axon Initial Segment; $\mathrm{BzAQ}$, Benzylamide-azobenzene-quaternary ammonium; $\mathrm{Ca}_{\mathrm{v}}$, voltage-gated calcium channel; DENAQ, diethylamine-azobenzene-quaternary ammonium; DREADDs, designer receptors exclusively activated by designer drugs; GABARs, gamma-amino butyric acid receptors; HCN, hyperpolarizationactivated cyclic nucleotide-gated; iGluR, ionotropic glutamate receptor; $\mathrm{K}_{\mathrm{ir}}$, inward-rectifier potassium channel; $\mathrm{K}_{\mathrm{v}}$, voltage-gated potassium channel; MAQ, maleimide-azobenzene-quaternary ammonium; nAChR, nicotinic acetylcholine receptor; $\mathrm{Na}_{\mathrm{v}}$, voltage-gated sodium channel; PCL, photochromic ligand; PhENAQ, phenylethylamine-azobenzene-quaternary ammonium; PrAQ, propylazobenzene-quaternary ammonium; PSAM, pharmacologically selective actuator modules; PSEM, pharmacologically selective effector molecules; PTL, photoswitchable tethered ligand; $\mathrm{QA}$, quaternary ammonium; $\mathrm{QAQ}$, quaternary ammonium-azobenzene-quaternary ammonium; RASSLs, receptors activated solely by synthetic ligands; RGC, retinal ganglion cell.
}

Zhang et al., 2007; Chow et al., 2010). The incredible success of these optogenetic tools lies in their versatility (they are one-component systems, as the chomophore retinal is naturally present in all vertebrate tissues) and their ability to be specifically targeted to desired neuronal populations (Fenno et al., 2011; Yizhar et al., 2011; Dugué et al., 2012). By overriding the electrical activity of neurons, microbial opsins can bring the membrane potential closer to or further away from the threshold for AP firing. These opsins can thus be used to link optically induced changes in activity of defined neurons with resultant circuit or behavioral effects. While advantageous for comprehending neural networks at a systems level, the optogenetic approach is ill-suited for understanding the intrinsic mechanisms regulating neuronal excitability on a molecular and cellular level. Light-sensitive modules from plants, such as phytochromes, cryptochromes, LOV domains or BLUF domains can be genetically coupled to mammalian proteins in order to gain optical control over protein-protein interactions, protein or DNA binding, enzymatic activity or subcellular protein localization (Möglich and Moffat, 2010; Pathak et al., 2012). LOV domains have been fused to the C-terminal fragment of Orail calcium channels to remotely control $\mathrm{Ca}^{2+}$ signaling (Pham et al., 2011). While attractive, this strategy may prove difficult to transpose to other ion channels. In contrast, caged compounds and reversible photoswitches are chemical molecules that have been used by neuroscientists to modulate the activity of endogenous ion channels in neurons (Goeldner and Givens, 2005). Cages allow for the photorelease of neurotransmitters and secondary messengers, triggering signaling events with temporal and spatial precision (Ellis-Davies, 
2007; Warther et al., 2010). However, since uncaging is an irreversible photochemical process, the duration of the elicited effect is dependent on the kinetics of diffusion or re-uptake of the photoreleased molecule. On the other hand, chemical photoswitches (Gorostiza and Isacoff, 2008; Beharry and Woolley, 2011; Fehrentz et al., 2011) can be used to modulate the activity of ion channels in a reversible fashion, allowing for many rounds of activation/deactivation (or inhibition/disinhibition). In this review we will describe our recent work on developing both one- and two-component photoswitchable systems for the optical control of voltage-gated ion channels and neuronal excitability.

\section{ONE-COMPONENT SYSTEMS: DEVELOPMENT AND TUNING OF PHOTOCHROMIC LIGANDS}

Photochromic ligands (PCLs) are light-sensitive molecules that can photo-isomerize after absorption of a photon. Photoisomerization induces a modification of the spectral, chemical, electronic and steric properties of the ligand, in a manner that can affect its biological activity (Beharry and Woolley, 2011;
Fehrentz et al., 2011). Several properties of azobenzene have made it the most-commonly used photoswitch for biological applications: (1) the trans to cis photoisomerization results in a drastic change in geometry (from planar to twisted, Figure 1A) and polarity (from $\sim 0$ to 3 Debye) (2) the absorption spectra of the two isomers are different enough (Figure 1B) to allow nearly-full conversion to cis or trans under the appropriate light conditions; (3) azobenzenes are relatively small, simple chemical moieties that can easily be conjugated to various ligands; (4) photoisomerization occurs on a picosecond time scale, orders of magnitude faster than most biological processes, and (5) azobenzenes are very photostable, allowing many cycles of photoisomerization without fatigue. Because the trans isomer is thermodynamically more stable than the cis isomer, it is the highly predominant form in the dark (>99.99\%).

Photoregulation of ion channels using PCLs was pioneered with the nicotinic acetylcholine receptor (nAChR) in the late 1960s (Deal et al., 1969; Bartels et al., 1971; Lester et al., 1979; Krouse et al., 1985) but only recently adapted to other ion
A

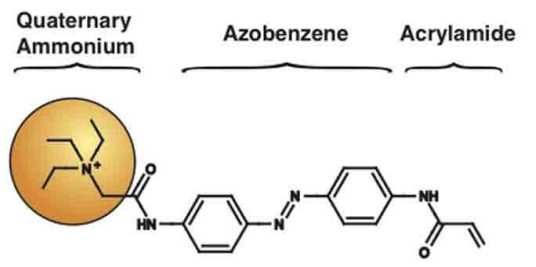

C

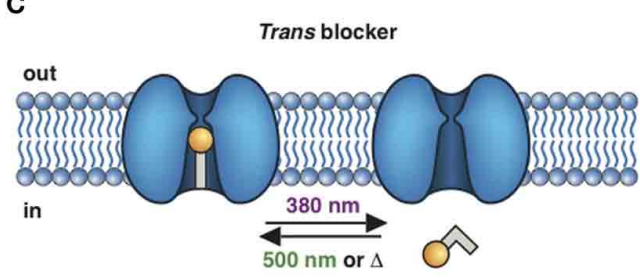

D

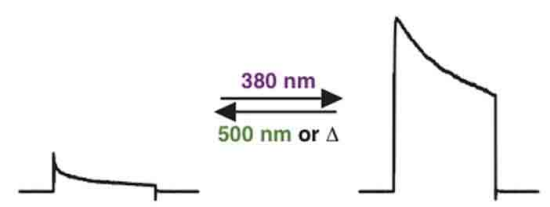

FIGURE 1 | Photoswitchable blockers for voltage-gated potassium channels. (A) Chemical structures of trans (left) and cis (right) AAQ (Acrylamide-Azobenzene-Quaternary ammonium). The quaternary ammonium moiety (ligand) is highlighted by a yellow sphere.

(B) Absorption spectrum of QAQ (Quaternary ammonium-AzobenzeneQuaternary ammonium) in the dark ( 100\% trans) and during illumination with $380 \mathrm{~nm}$ light (mostly cis). (C) Scheme of a trans blocker. The blocker binds to the intracellular vestibule and blocks ion conduction through voltage-gated potassium channels in the trans configuration $(500 \mathrm{~nm}$ light or darkness) but not after photoisomerization

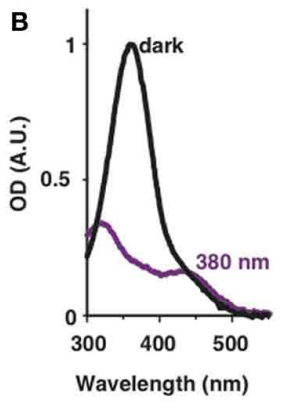

E

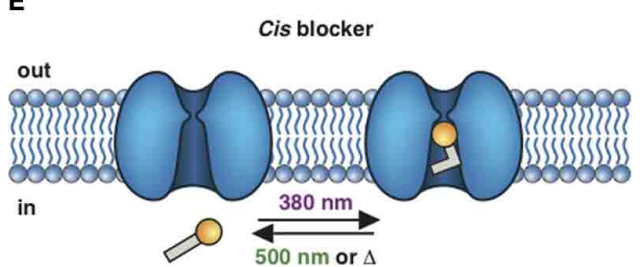

F

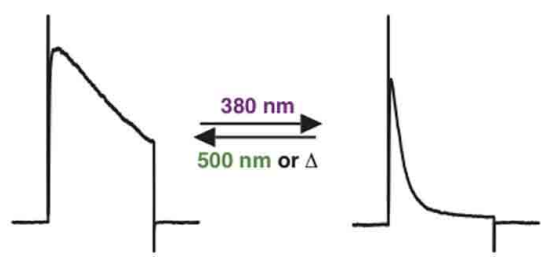

to cis $(380 \mathrm{~nm})$. (D) Example of a voltage-clamp recording of current through voltage-gated potassium channels after depolarization of the membrane, using a trans blocker under 500 or $380 \mathrm{~nm}$ light illumination. (E) Scheme of a cis blocker. The blocker binds to the intracellular vestibule and blocks ion conduction through voltage-gated potassium channels in the cis configuration $(380 \mathrm{~nm}$ light) but not in the dark or after photoisomerization to trans $(500 \mathrm{~nm})$. (F) Example of a voltage-clamp recording of current through voltage-gated potassium channels after depolarization of the membrane, using a cis blocker under 500 or $380 \mathrm{~nm}$ light illumination. $\Delta$ : thermal relaxation in the dark. 
channels, such as the ionotropic glutamate (Volgraf et al., 2007; Stawski et al., 2012) and gamma-amino butyric acid receptors (GABARs) (Stein et al., 2012; Yue et al., 2012). Following a similar strategy, we have developed a small library of PCLs that block voltage-gated potassium channels $\left(\mathrm{K}_{\mathrm{V}} \mathrm{s}\right)$ in a photo-reversible fashion (Fortin et al., 2008; Banghart et al., 2009; Mourot et al., 2011, 2012; Fehrentz et al., 2012). Quaternary ammoniums (QAs) inhibit $\mathrm{K}_{\mathrm{V}}$ s by entering the intracellular vestibule and blocking $\mathrm{K}^{+}$ conduction (Choi et al., 1993). We designed photoswitchable $\mathrm{K}_{\mathrm{v}}$ blockers with a central azobenzene core, flanked on one side by a QA "head" and on the other side by a hydrophobic "tail". The initial "tail" was an acrylamide moiety, and the compound was named Acrylamide-Azobenzene-Quaternary ammonium (AAQ) (Figure 1A) (Fortin et al., 2008). The reactive acrylamide group was chosen because AAQ was originally designed to covalently attach to the outer mouth of native $K_{v}$ s (Fortin et al., 2008), but further investigation revealed that, due to its hydrophobic "tail," AAQ was in fact able to cross the cell membrane and non-covalently bind to the internal vestibule (Banghart et al., 2009). AAQ is a trans blocker of $K_{V} s$, that is, the trans isomer has a much higher affinity for the internal vestibule than the cis form. In the dark or under $500 \mathrm{~nm}$ illumination, channels will be blocked by AAQ, whereas $380 \mathrm{~nm}$ light will relieve the blockade and restore $\mathrm{K}^{+}$conduction (Figures 1C,D). AAQ is a trans blocker for the Shaker $\mathrm{K}^{+}$channel, but also for a wide range of mammalian $\mathrm{K}_{\mathrm{v}} \mathrm{s}$ heterologously expressed or naturally present in neurons (Table 1).

Each biological application requires a specific set of characteristics. Photoswitchable $\mathrm{K}_{\mathrm{v}}$ blockers can be easily modified using the power of organic chemistry, enabling us to generate a small library of compounds with various pharmacological and photophysical properties (Table 1) (Banghart, 2009; Mourot et al., 2013). AAQ is a permanently charged molecule that must cross the cell membrane to photosensitize $\mathrm{K}^{+}$channels. Membrane permeation has been experimentally verified for AAQ (Banghart et al., 2009) and has been observed for other permanently charged drugs like the local anesthetics tonicaine (Wang et al., 1995) and tetra-pentylammonium (Taglialatela et al., 1991). In all the aforementioned cases, the charged molecule accumulates inside the cell where it is trapped for hours, more than $24 \mathrm{~h}$ in the case of AAQ loaded into dissociated hippocampal neurons (Banghart et al., 2009). Replacing the acrylamide "tail" with a more hydrophobic benzylamide moiety results in a molecule (BzAQ) with better membrane permeation, as evidenced by the drastic increase in potency when the PCLs are applied outside cells (see working concentration for AAQ an BzAQ in Table 1) but a similar potency when the compounds have direct access to the internal vestibule (Banghart et al., 2009). Doing the opposite, i.e., replacing the acrylamide chain with a more polar, charged QA group results in a compound (QAQ) ineffective at crossing the cell membrane. Of note, some of the most hydrophobic compounds, e.g., PhENAQ, suffer from lack of water solubility.

Chemical modifications can also affect the pharmacology of the PCLs. AAQ photosensitizes most, but not all $\mathrm{K}_{\mathrm{V}} \mathrm{s}$; for example, current through $\mathrm{K}_{\mathrm{v}} 3.1$ is not affected by AAQ (Fortin et al., 2008). Similarly, DENAQ photosensitizes many $K_{v} s$ but not Shaker which belongs to the $K_{V} 1$ family (Mourot et al., 2011).
QAQ, on the other hand, not only photosensitizes $K_{v} s$ but also voltage-gated $\mathrm{Na}^{+}$and $\mathrm{Ca}^{2+}$ channels $\left(\mathrm{Na}_{\mathrm{V}} \mathrm{s}\right.$ and $\mathrm{Ca}_{\mathrm{V}} \mathrm{s}$, respectively) (Mourot et al., 2012), which are structurally related to $K_{v} s$ and also blocked by intracellular QAs (Scholz, 2002). Of all the PCLs tested, only the ones with two QA groups seem to block $\mathrm{Na}_{\mathrm{V}} \mathrm{s}$ (Table 1). The identity of the biologically active isomer also depends on the chemical nature of the "tail." For example AAQ, $\mathrm{BzAQ}$, and QAQ are trans blockers of $\mathrm{K}_{\mathrm{V}} \mathrm{s}$, that is, they block preferentially in the trans configuration, but other PCLs such as PrAQ or PhENAQ are cis blockers (Table 1 and Figures 1E,F). In the absence of illumination, PCLs exist in only one form: the thermally stable trans isomer. Cis blockers can be advantageous for certain applications as they are inert in the dark (assuming the trans isomer does not block at all) and activate only after illumination with the appropriate wavelength of light. Understanding the molecular features necessary for the recognition of the cis or the trans isomer by various ion channels is crucial to the rational design of more selective PCLs. Alas, this is not a straightforward task, since it requires the synthesis and screening of a large library of compounds in addition to molecular modeling of the PCLs bound to the channel.

The wavelength used to isomerize AAQ from trans to cis is in the near-UV range $(380 \mathrm{~nm})$, which is compatible with biological systems. However, there is a clear interest in developing PCLs with a red-shifted spectrum, as longer wavelengths of light are less phototoxic and penetrate deeper into tissue. Many of the phenyl ring substituents are known to alter the spectral characteristics of azobenzenes and this effect can be rationally utilized to design novel azobenzene derivatives (Rau, 1973; Beharry and Woolley, 2011). For example, electron donating groups at the ortho or para positions can red-shift the absorption spectrum of the trans isomer considerably (Chi et al., 2006; Sadovski et al., 2009; Beharry et al., 2011, 2008; Stawski et al., 2012). We have designed PCLs where the amide tail of AAQ was replaced by electron donating amine tails (see DENAQ and PhENAQ in Table 1). The new PCLs are red-shifted by up to $100 \mathrm{~nm}$, enabling the photocontrol of $K_{v} s$ with blue light (480 nm) (Mourot et al., 2011). The Trauner group has also developed derivatives of QAQ with electron donating groups in the ortho position (see 2,2'-dimethoxy QAQ in Table 1), but this resulted in only a minor red-shift $(\sim 30 \mathrm{~nm})$ and in some cases compounds that were ineffective at blocking voltage-gated ion channels (Fehrentz, 2012; Fehrentz et al., 2012). The internal vestibule of $\mathrm{K}_{\mathrm{v}} \mathrm{s}$ may be too tight to accommodate bulky substituents in the ortho position, but seems to accommodate rather long, bulky, hydrophilic or hydrophobic "tails" in the para position.

Once light is turned off, the cis isomer relaxes back to the more stable trans form, yielding essentially $100 \%$ of the trans isomer. The kinetics of thermal relaxation are highly dependent on the substituents located on the phenyl rings of the azobenzene (Beharry and Woolley, 2011). For example, the half-life of cis QAQ in aqueous solution $\left(\mathrm{t}_{1 / 2}\right)$ is in the $7 \mathrm{~min}$ range, but can be extended to hours and even days after adding methyl groups in the ortho position (see di- and tetra-methyl QAQs in Table 1). Continuous light exposure is not required to maintain these thermo-stable compounds in their cis form. This can be advantageous in cases where constant illumination would be 


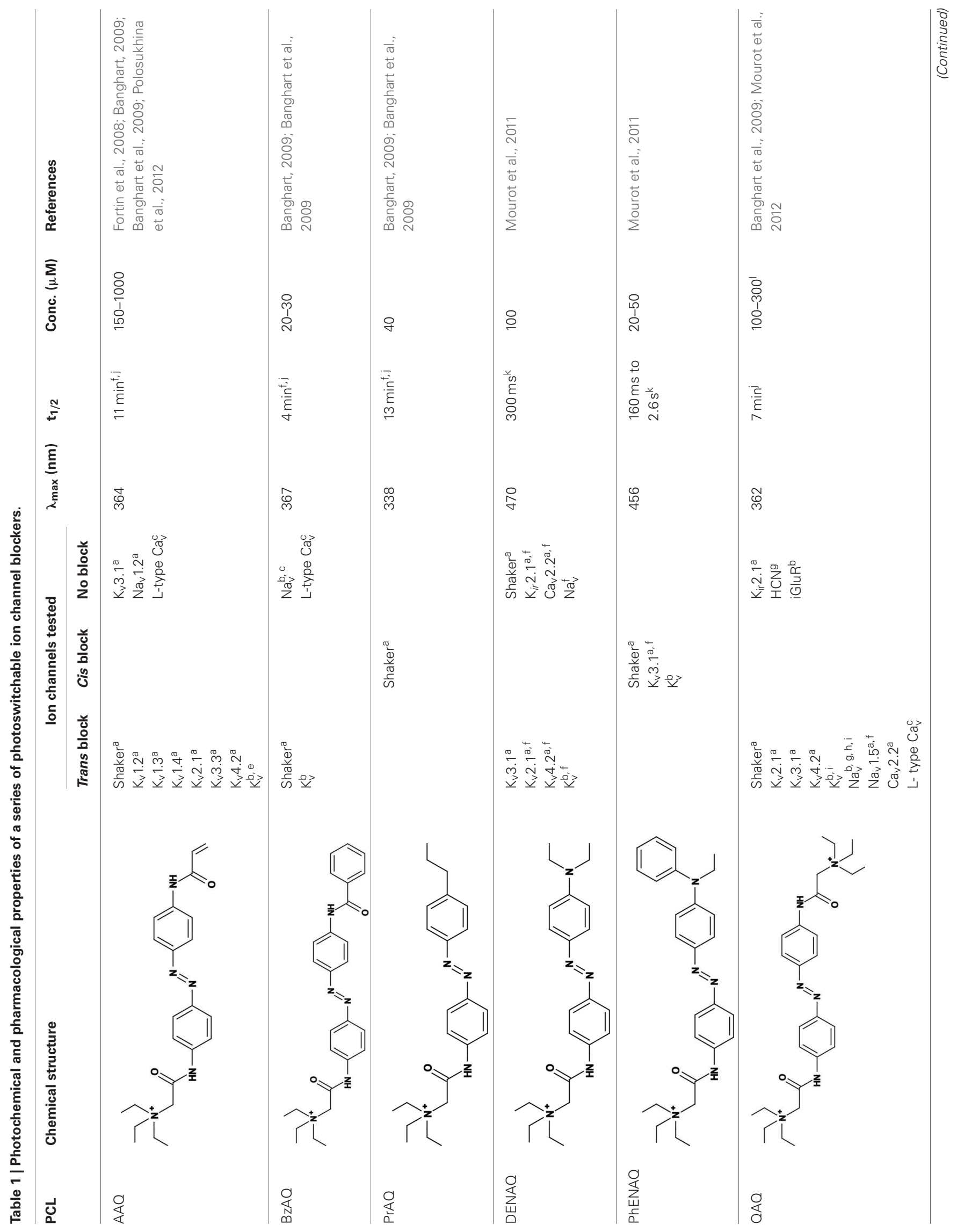




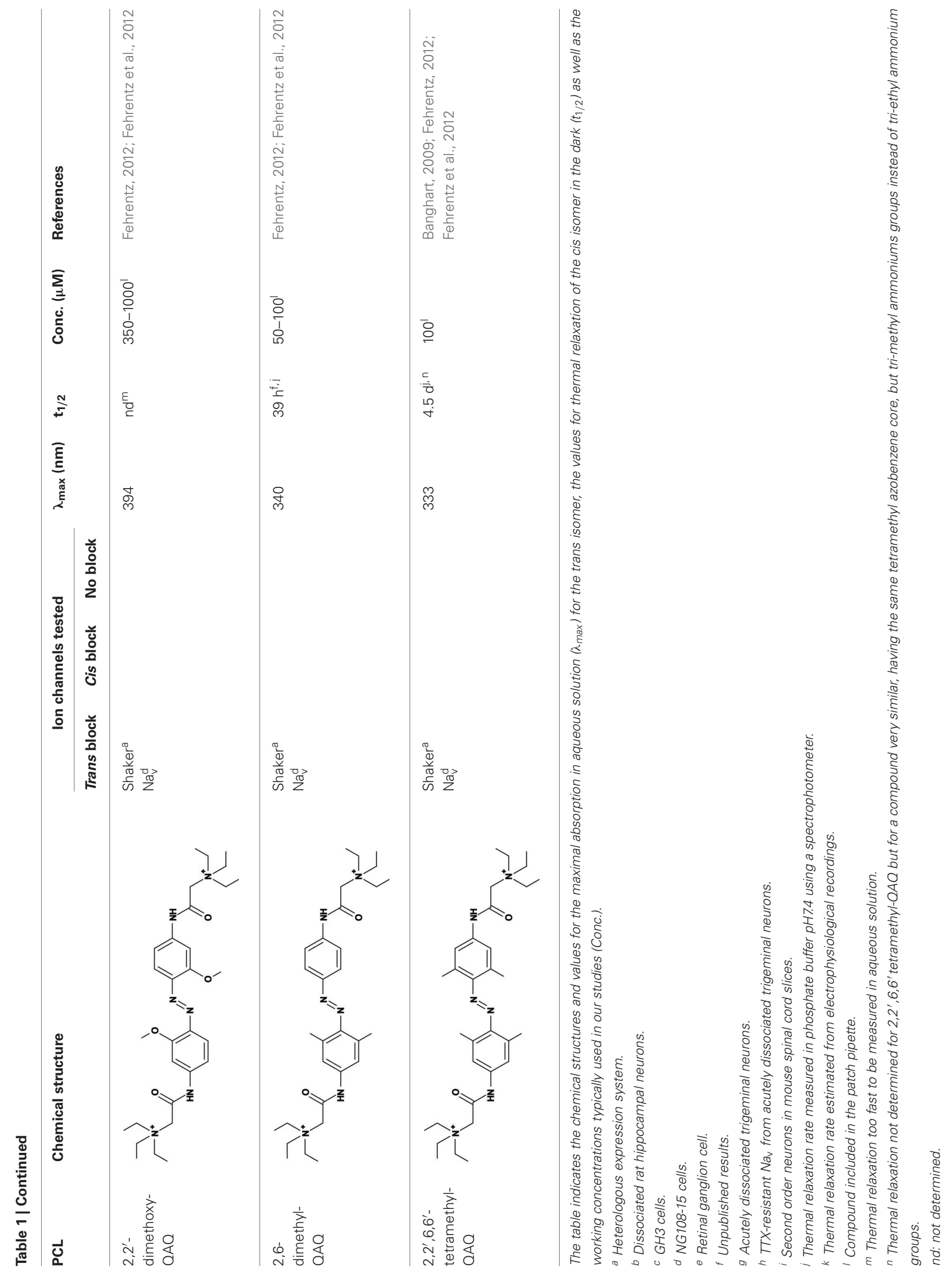


toxic, impractical or simply not technically feasible. Conversely, thermal relaxation can also be sped up. The fastest thermal relaxation reported to date for an azobenzene derivative in water is in the nanosecond range (Garcia-Amorós et al., 2012). Rapid thermal relaxation is desirable, since a single wavelength of light can then be used to quickly toggle the photoswitch between its two isomers. However, it is not necessarily ideal, since very intense illumination is required to accumulate enough of a very short-lived isomer to produce a significant biological effect. The red-shifted PCLs we have engineered have much faster relaxation kinetics than QAQ, too fast, in fact, to be measured using classical spectrophotometers (Fehrentz et al., 2012), but estimated to be in the hundreds of millisecond range using electrophysiological recordings (Mourot et al., 2011). This value is in agreement with the reported half-lives in the tens of milliseconds range for similar amino-azobenzenes (Chi et al., 2006). Despite their short half-lives, some red-shifted PCLs block a considerable fraction of the channel's ionic current, suggesting a significant accumulation of the cis isomer (Mourot et al., 2011; Fehrentz et al., 2012). Importantly, because the spectra of the two amino-azobenzene isomers overlap substantially (Beharry and Woolley, 2011), light cannot be used to trigger the reverse isomerization to the trans form. Therefore, rapid thermal relaxation is a necessary feature for the rapid and reversible photocontrol of neuronal activity with such red-shifted azobenzenes. New types of red-shifted azobenzenes show a substantial separation in the spectra of the two isomers, making it possible to use two different wavelengths of visible light for rapidly accumulating a high percentage of either the cis or the trans isomer (Beharry et al., 2011; Bléger et al., 2012).

What fraction of the cis isomer can be generated under our experimental conditions? Since cis and trans azobenzenes have partially overlapping spectra, illumination produces a photostationary state with a certain percentage of each isomer. Using the appropriate wavelength of light, a large fraction of the photoswitch molecules can be isomerized to cis or to trans (Beharry and Woolley, 2011). Precise determination using ${ }^{1} \mathrm{H}$ NMR revealed that up to $95 \%$ of the photoswitch can be converted to cis under illumination with $380 \mathrm{~nm}$ (Gorostiza et al., 2007; Banghart and Trauner, 2013). In order to obtain an estimate of the percentage of the cis isomer under physiological conditions, we measured the concentration of two PCLs, AAQ and BzAQ, that blocked half of the Shaker $\mathrm{K}^{+}$channel current, both in the dark and under $380 \mathrm{~nm}$ illumination $\left(\mathrm{IC}_{50 \text { (dark) }}\right.$ and $\mathrm{IC}_{50(380 \mathrm{~nm}) \text {, respec- }}$ tively) (Banghart et al., 2009). These two PCLs have identical azobenzene chromophores, with two amide groups in the para position, and therefore should have similar photochemical properties. We found the $\mathrm{IC}_{50(380 \mathrm{~nm})} / \mathrm{IC}_{50 \text { (dark) }}$ ratio to be 28 and 42 for AAQ and BzAQ, respectively. Assuming cis AAQ and cis BzAQ bind to Shaker $\mathrm{K}^{+}$channels with negligible affinity, the percentage of the trans molecule under $380 \mathrm{~nm}$ light illumination is $1 / 28=3.5 \%$ for $A A Q$, and $1 / 42=2.4 \%$ for BzAQ. If the affinity of cis AAQ or cis BzAQ for Shaker $\mathrm{K}^{+}$channels is not negligible, then the percentage of the trans PCL under $380 \mathrm{~nm}$ light is even lower. Hence, it is possible to obtain more than $96 \%$ photoisomerization to the cis form using AAQ, BzAQ or other PCLs with similar photoswitches. As mentioned above, the situation may be different with quickly relaxing compounds like DENAQ or PhENAQ.

\section{OPTICAL CONTROL OF ACTION POTENTIAL FIRING WITH PCLs}

The molecular mechanism underlying the initiation and propagation of AP is the opening and closing of voltage-gated ion channels (Hille, 2001). When excitatory inputs to a neuron trigger a depolarization above the AP initiation threshold (typically $-50 \mathrm{mV}$ ), $\mathrm{Na}_{\mathrm{v}}$ s quickly open and sodium ions rush into the cell, depolarizing the membrane even further. After a slight delay, $\mathrm{Na}_{V} s$ inactivate and $\mathrm{K}_{\mathrm{V}} \mathrm{s}$ start to open, thus generating a potassium efflux that repolarizes the cell membrane. $\mathrm{K}_{\mathrm{V}} \mathrm{s}$ and other $\mathrm{K}^{+}$channels (e.g., calcium-activated $\mathrm{K}^{+}$channels) do not close immediately after the membrane returns to its resting membrane voltage, generating a hyperpolarization phase called afterhyperpolarization (AHP), during which the neuron is refractive to subsequent AP. Therefore, the influx and efflux of sodium and potassium ions shape APs, and rapidly photoregulating their flux should give us control over AP firing.

When neurons are at rest, some $\mathrm{K}_{\mathrm{V}} \mathrm{s}$, notably the low-voltage activated ones, are open and play a role in maintaining and regulating the membrane potential (Hille, 2001). Blocking them can result in membrane depolarization and increase neuronal activity. AAQ, which is a photoswitchable blocker selective for $\mathrm{K}^{+}$ channels, can be used to optically increase neuronal excitability and induce AP firing (Fortin et al., 2008). In the dark or under green light, AAQ blocks neuronal $\mathrm{K}_{\mathrm{V}} \mathrm{s}$, depolarizes the cell membrane and enables high-frequency firing (Figure 2A). Subsequent photoisomerization to cis with $380 \mathrm{~nm}$ light, which unblocks $\mathrm{K}_{\mathrm{V}} \mathrm{s}$, hyperpolarizes the membrane and reduces neuronal excitability. Comparing the AP shapes under both wavelengths of light clearly shows that the peak is unaltered, while hyperpolarization is reduced under $500 \mathrm{~nm}$ light, consistent with the selective block of $\mathrm{K}^{+}$channels (Figure 2B). Optical regulation of membrane excitability with AAQ works well not only in cultured neurons, but also in rat cerebellar slices, in the heart central pattern generator of leeches, as well as in mice retinal neurons in vitro and in vivo (Fortin et al., 2008; Polosukhina et al., 2012). One limitation of AAQ is that, in the absence of illumination, the trans configuration dominates, leading to a tonic block of $\mathrm{K}_{\mathrm{V}} \mathrm{s}$ and potential cytotoxicity. Cis blockers like PhENAQ could offer significant advantage by minimizing basal excitation in the dark (Mourot et al., 2011).

QAQ has a different effect on neuronal excitability: it does not modulate the resting membrane potential, but prevents AP firing when neurons receive excitatory inputs, by blocking all voltagegated ion channels, i.e., $\mathrm{K}_{\mathrm{v}} \mathrm{s}, \mathrm{Na}_{\mathrm{v}} \mathrm{s}$ and $\mathrm{Ca}_{\mathrm{V}} \mathrm{s}$ (Mourot et al., 2012). When illuminated with $500 \mathrm{~nm}$ light, neurons loaded with QAQ fire a single AP at the onset of current injection, followed by depolarization block and absence of repetitive spiking (Figure 2C). The presence of the first spike can be attributed to the nature of the molecular interaction between trans QAQ and ion channels: QAQ is an open-channel blocker, that is, ion channels must first open before QAQ can bind and block ion conduction (Hille, 2001; Mourot et al., 2012). Under $380 \mathrm{~nm}$ light, ionchannel block is relieved and neurons can fire at a high-frequency. 

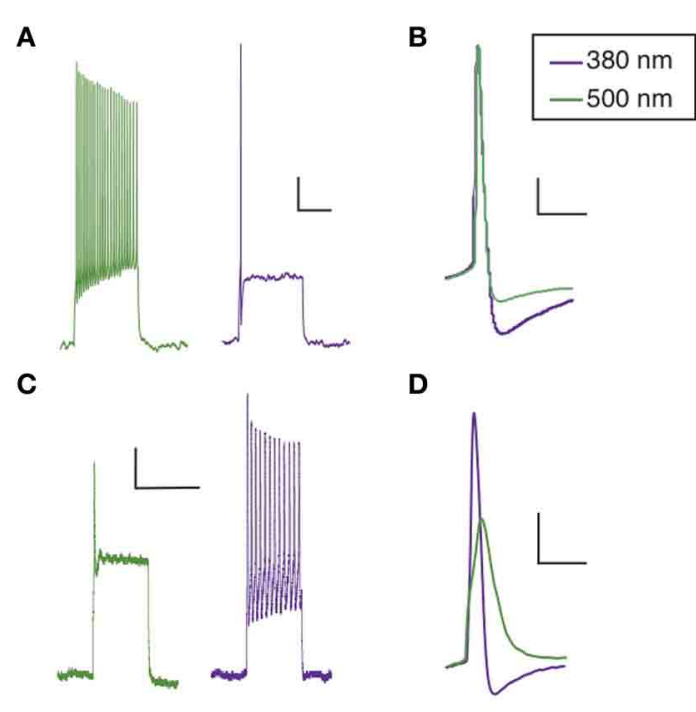

D

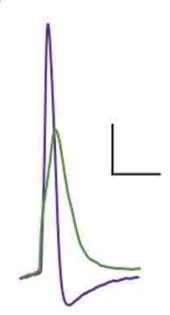

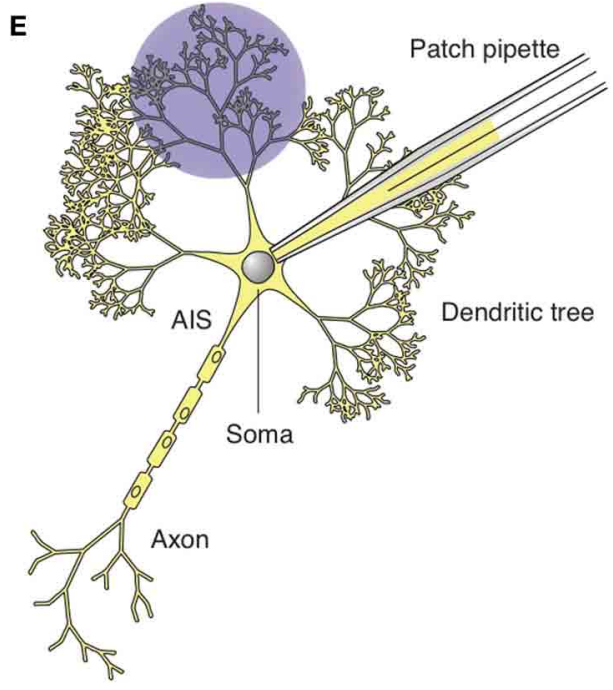

FIGURE 2 | Optical control of AP firing in hippocampal neurons using

PCLs. (A) Current clamp recording of a hippocampal neuron in culture treated with $A A Q$, showing the effect of light on neuronal excitability. (B) AP shape in both wavelength of light for an AAQ-treated hippocampal neuron. (C) Current clamp recording of a hippocampal neuron in culture loaded with $\mathrm{QAQ}$ through the patch pipette, showing the effect of light on spike inhibition. (D) AP shape in both wavelength of light for a neuron loaded with QAQ. (E) Patterned illumination for the optical control of the excitability of a dendritic tree using $\mathrm{QAQ}$ loaded through the patch pipette. The main regions of a neuron are indicated. Scale bars (A,C) $10 \mathrm{mV}, 500 \mathrm{~ms}$; (B,D) $10 \mathrm{mV}, 25 \mathrm{~ms}$.
Due to the block of both $\mathrm{K}_{\mathrm{V}} \mathrm{s}$ and $\mathrm{Na}_{\mathrm{v}} \mathrm{s}$, the AP amplitude is reduced and its half-width increased under $500 \mathrm{~nm}$ compared to $380 \mathrm{~nm}$ light (Figure 2D). QAQ blocks $\mathrm{Na}_{\mathrm{v}} \mathrm{s}$ only partially, yet it potently silences cells, probably because its blockade of $\mathrm{K}^{+}$ channels potentiates blockade of $\mathrm{Na}^{+}$channels (Drachman and Strichartz, 1991).

Neuronal dendrites receive, coordinate and integrate thousands of excitatory and inhibitory inputs (Magee and Johnston, 2005). Inputs are integrated at the level of the soma and APs are initiated in a specialized, unmyelinated element of the neuron called the axon initial segment (AIS), before they propagate through the rest of the axon (Kole and Stuart, 2012). In some neurons, such as hippocampal and cortical pyramidal neurons, APs can also back-propagate from the soma to the dendrites, which is essential to many forms of synaptic plasticity (Magee, 1997; Markram, 1997; Magee and Johnston, 2005). The presence of a high density of specialized voltage-gated ion channels is essential to the electrical properties of AIS, axons and dendrites. Yet, manipulating these ion channels in specific subcellular domains of a neuron is technically challenging. Local perfusion of tetrodotoxin, a specific $\mathrm{Na}_{\mathrm{v}}$ blocker, has been used to show that back-propagation of APs is required for the induction of synaptic plasticity (Magee, 1997), but this can only be done in large neurons with dendritic trees long-enough to confine tetrodotoxin to the desired location. Membrane-impermeant ion-channel blockers like QX-314 can also be used to eliminate excitability in dendrites and axons of single neurons, making it possible to pharmacologically isolate synaptic from non-synaptic events and elucidate the composition of the synaptic responses (Smirnov et al., 1999; Wilent and Contreras, 2005). Because QX314 is membrane-impermeant (Strichartz, 1973; Binshtok et al.,
2007), it can be dialyzed into cells through a patch pipette, but once inside, it cannot be removed; therefore its action is irreversible. In contrast to chemical ligands, light can be delivered onto tissues with great spatial resolution, and recent optical techniques even allow for patterned illumination in three dimensions (Vaziri and Emiliani, 2012). Therefore, photoconvertible ligands such as the ones we have developed could be extremely useful in understanding the roles of voltage-gated ion channels in controlling dendritic and axonal excitability, especially in compact neurons. QAQ, which is essentially a photoswitchable derivative of QX-314 (Mourot et al., 2012), can open the way to new experimental opportunities. Because light can be projected with great spatial precision, it might be possible to control APs in particular parts of a neuron, such as a branch of the dendritic tree or the AIS (Figure 2E). For example, QAQ could be used to reversibly block back-propagating APs with a cellular precision that is hard to achieve with externally applied blockers (Magee, 1997), and help evaluate the contribution of dendritic excitability to synaptic integration and plasticity.

\section{CELL TARGETING WITH QAO}

Optogenetic tools have one advantage over PCLs: they can be targeted to genetically defined cell types using either specific promoters or cre recombinase-inducible expression systems in conjunction with transgenic animals expressing cre in specific population of neurons (Fenno et al., 2011; Yizhar et al., 2011; Dugué et al., 2012). Cell targeting is essential for establishing a causal relationship between the activity pattern of a defined population of neurons and the function of that neuronal population at the circuit or behavioral level. Even though QAQ is not 
genetically encodable, we have designed a strategy for delivering it to a defined sub-population of neurons.

QAQ is a doubly charged (Figure 3A), membraneimpermeant PCL that does not enter most cells when applied extracellularly. However, we found that QAQ was able to enter cells through open TRPV1 and some P2X channels, enabling the targeted photosensitization of cells expressing either of these channels (Mourot et al., 2012). TRPV1 channels are heat-activated channels required for the detection of noxious heat (Caterina et al., 1997), while P2X receptors are ion channels activated by extracellular ATP (Valera et al., 1994). One biophysical property shared by these two ion channel types is their ability to allow large organic cations to pass through the channel pore (Khakh et al., 1999; Virginio et al., 1999; Meyers et al., 2003; Chung et al., 2008; Binshtok et al., 2007). We took advantage of this property to deliver QAQ into specific cells, utilizing these channels as "molecular conduits" (Figure 3B).

TRPV1 channels are highly expressed in pain fibers but scarcely present in the central nervous system (CNS) (Arenkiel et al., 2008; Cavanaugh et al., 2011). P2X receptors are primarily expressed in the peripheral nervous system and in epithelial and endothelial tissue, but are also present to some extent at a few central synapses (Khakh and North, 2006). Because both channels and their respective agonists, capsaicin and ATP, are nearly absent from the CNS, heterologous expression of TRPV1 or P2X channels could be used as an orthogonal way of optically silencing genetically identified neurons with QAQ (Mourot et al., 2012). Miesenböck and colleagues designed a comparable optochemical genetic strategy to remotely photoactivate specific neurons heterologously expressing TRPV1 or P2X channels, using

A
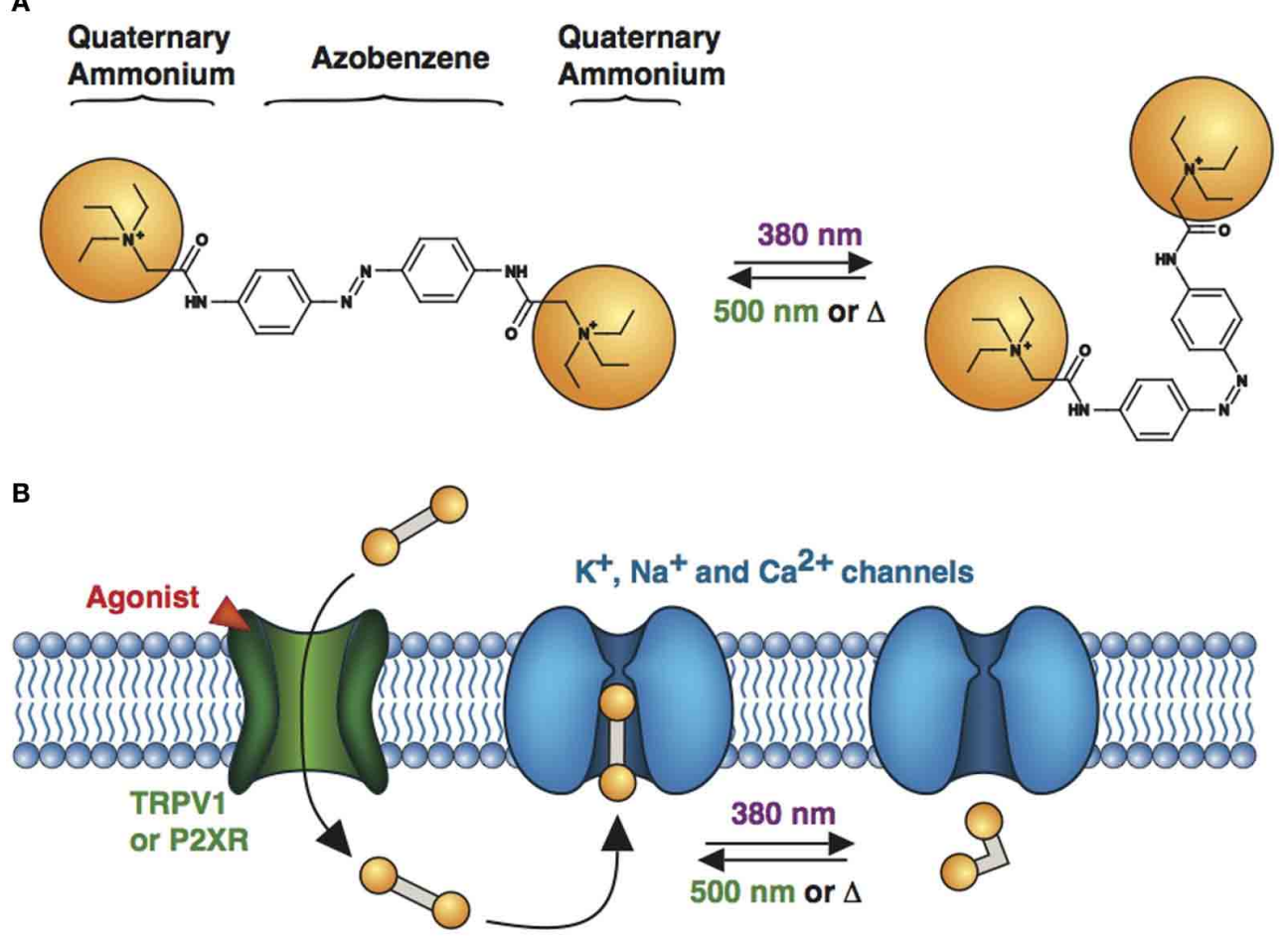

C

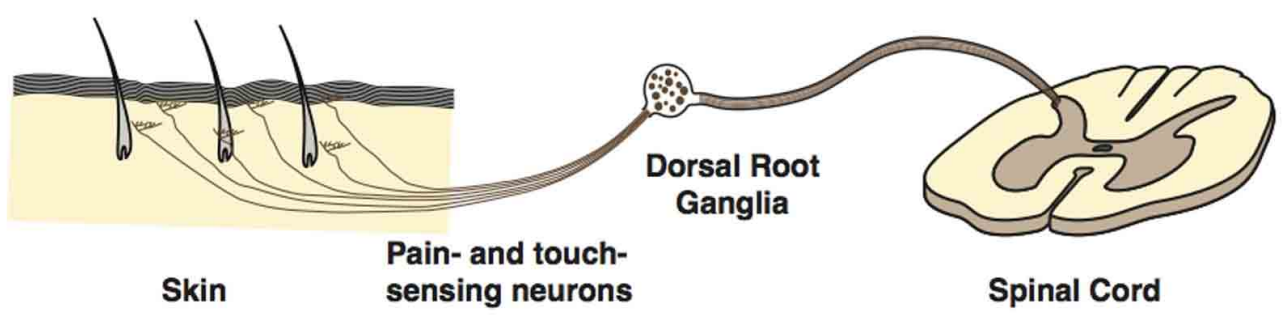

FIGURE 3 | Cell targeting strategy with QAQ. (A) Chemical structures of trans (left) and cis (right) $\mathrm{QAQ}$. (B) $\mathrm{QAQ}$ is membrane impermeable, but can enter cells through open TRPV1 or P2XR channels. Once in the cystosol, $\mathrm{QAO}$ photosensitizes voltage-gated $\mathrm{K}^{+}, \mathrm{Na}^{+}$, and $\mathrm{Ca}^{2+}$ channels. (C) Touch- and pain-sensing neurons innervate the skin and project to the spinal cord. Their cell bodies are located in the dorsal root ganglia. QAQ can be targeted specifically to pain-sensing neurons, which contain high densities of TRPV1 channels. 
caged-capsaicin or caged-ATP, in living flies (Zemelman et al., 2003; Lima and Miesenbock, 2005; Claridge-Chang et al., 2009). While elegant and powerful, both approaches suffer from the technical complexities associated with the expression of foreign genes and the subsequent delivery of photosensitive chemicals.

However, exogenous expression of TRPV1 or P2X receptor is not always necessary to target QAQ-induced photosensitivity to specific neurons. We took advantage of the intrinsic TRPV1 expression pattern to specifically deliver QAQ to painsensing neurons in rodents. Co-application of QAQ and capsaicin resulted in the selective entry of QAQ into pain-sensing neurons (aka nociceptors) both in vitro and in vivo, without affecting neighboring cells such as touch-sensing neurons, which are devoid of TRPV1 channels (Mourot et al., 2012). Sensory neurons are pseudo-unipolar neurons, with a peripheral process that carries AP to the cell body (located in the dorsal root ganglia), and a central process that carries AP to the post-synaptic neuron in the spinal cord (Figure 3C). The peripheral axons of nociceptors are usually extremely long and mixed together with other sensory neurons. Hence it has been extremely difficult to manipulate the activity of these neurons in a specific manner using current electrophysiological or pharmacological tools. Because QAQ can enter nociceptors at the level of their cell bodies, their synaptic terminals or their sensory nerve endings, our method enables the rapid control of pain signaling with a high degree of precision. This method will undoubtedly prove useful for understanding pain circuitry and pain signaling, in both physiological and pathological conditions.

\section{TWO-COMPONENT SYSTEMS: DEVELOPMENT OF DESIGNER PHOTORECEPTORS}

The various voltage- and ligand-gated ion channels found in neurons have very distinct biophysical properties as well as different subcellular and cellular distributions, but often share overlapping pharmacology. The limited selectivity of pharmacological agents has hindered the understanding of their physiological roles. Traditional drugs often cannot differentiate between different receptor types or subtypes. Some of them, such as toxins, do show good receptor selectivity, but their temporal action profile cannot mimic the rapid rise and fall in neurotransmitter concentrations in the brain, as they persist in the tissue for an extended period of time and cannot be washed out quickly. In addition, the effect of traditional pharmacological agents cannot be easily restricted to a specific cell type or tissue; for example, there is no method for selectively controlling post- vs. pre-synaptic receptors. The relationship between receptor function and behavior can also be studied via the generation of transgenic organisms, but this strategy lacks temporal specificity and can produce animal phenotypes where undesirable developmental defects and compensatory changes are superimposed on the true effects of receptor removal. The development of spatially and temporally targeted activation/inactivation of specific receptors will help to overcome this problem and produce a better understanding of the function of receptors in adult animals.

A number of chemical genetic strategies have been developed to overcome the limitations of conventional pharmacology. They combine the powers of chemistry and genetic targeting to enable an unparalleled degree of pharmacological specificity (Rogan and Roth, 2011; Wulff and Arenkiel, 2011). One strategy involves designing a combination of chemically modified small molecule ligands and mutant receptors that specifically bind these ligands. The modified ligands are considered "orthogonal" in normal cells, since they should not bind any wild-type receptor, but only their mutant partner. This approach was first demonstrated on a mutant $\kappa$ opiod receptor, which was engineered to dramatically reduce its affinity for the endogenous ligand dynorphin, but still respond to synthetic small molecule drugs (Coward et al., 1998). This type of receptor activated solely by synthetic ligands was called a RASSL. The receptor-ligand pair strategy was later extended to create other mutant $G$ protein-coupled receptors with lower baseline activity. These second generation designer receptors exclusively activated by designer drugs were named DREADDs (Armbruster et al., 2007). Ligand-gated ion channels, including GABARs (Wulff et al., 2007) and nAChRs (Magnus et al., 2011) were also engineered to be orthogonal to certain ligands. In the case of nAChRs, a variety of pharmacologically selective effector molecules (PSEMs) and pharmacologically selective actuator modules (PSAMs) were generated, with different ionic permeabilities for remotely exciting or silencing targeted neurons. The mutant receptors may retain their original function, in which case the receptor-ligand pair is used to define the biological roles of the receptor (Wulff et al., 2007). Conversely, the receptor may only possess the ability to bind the orthogonal ligand but not the endogenous neurotransmitter, in which case the receptor becomes orthogonal as well and is used to remote control cellular signaling or membrane excitability in genetically targeted cells (Armbruster et al., 2007; Magnus et al., 2011). However, though this chemical genetic approach has produced highly specific receptor-ligand combinations that work well both in vitro and in vivo, it still suffers from the lack of fine spatiotemporal control of receptor activity, due to the inability to control ligand diffusion into or out of a region of interest or manipulate the dynamics of ligand binding/unbinding. Light is the perfect modality for achieving such precise spatiotemporal control, as it allows for micrometer spatial and millisecond temporal resolution. We thus decided to combine the power of chemical genetics with the precision of optical control in order to develop a series of photoswitchable tethered ligands (PTLs) for the optochemical genetic control of ion channels (Fehrentz et al., 2011).

The PTL strategy involves the genetic engineering of receptors and their conjugation to a chemical photoswitch, allowing light to precisely activate or inhibit that receptor subtype in a given neuronal population. The PTL contains a ligand (agonist or pore blocker/antagonist) on one end of the molecule, a central photoisomerizable azobenzene core, and a cysteine-reactive group on the other end of the molecule. The PTL can react with engineered cysteine point mutations in the ion channel of interest, covalently tethering the ligand to the receptor. In addition to the shape and dipole moment changes, the end-to-end distance of the trans and cis isomers is also substantially different, allowing light to toggle the ligand in and out of its binding pocket. Photoisomerization of the PTL thus leads to a reversible activation or inhibition of the receptor. Such a strategy allows us to control an individual ion channel subtype in a neuron, i.e., the one containing 
the cysteine mutation, with high spatiotemporal precision, while leaving native channels unaffected. Importantly, the functionality of the mutant receptor should remain unchanged prior to PTL treatment, but its activity would then be controlled by light after conjugation of the PTL. Because designer channels can be genetically targeted, they belong to the family of optogenetic tools, even though they need a photochemical co-factor for functioning.

PTLs were first designed for the voltage-gated Shaker $\mathrm{K}^{+}$ channel, resulting in synthetic photoisomerizable azobenzeneregulated $\mathrm{K}^{+}$(SPARK) channels (Banghart et al., 2004; Chambers et al., 2006) that could be blocked and unblocked by light. SPARK channels are cysteine-containing mutant Shaker $\mathrm{K}^{+}$channels, which can be conjugated to a photoswitchable ligand, maleimideazobenzene-quaternary ammonium (MAQ, Figure 4A), containing the pore blocker QA. QAs not only block $\mathrm{K}^{+}$channels at the level of the inner vestibule, but also at an external binding site located just outside the selectivity filter (Hille, 2001). After MAQ conjugation, the QA moiety can reach the ion channel's outer pore only in the trans but not the cis configuration, which results in conduction block under $500 \mathrm{~nm}$ light or in the dark, when the PTL is in the trans form (Figures 4B,C). Illumination with $380 \mathrm{~nm}$ light converts the PTL to its shorter cis form, unblocking the ion channel and allowing for current flow. At low micromolar concentration, MAQ does not cross the cell membrane, ensuring specific optical control of the engineered cysteine mutant channel (Fortin et al., 2011; Sandoz et al., 2012). Expression of SPARK channels in neurons enabled the photocontrol of neuronal activity (Banghart et al., 2004; Chambers et al., 2006). However, because Shaker is a Drosophila $\mathrm{K}^{+}$channel, it is orthogonal to mammalian neurons and is therefore unsuited for the study of endogenous $\mathrm{K}^{+}$channel function in the mammalian CNS. We have thus decided to transpose the strategy to mammalian $\mathrm{K}^{+}$channels. Tethering MAQ onto engineered cysteine mutants of $\mathrm{K}_{\mathrm{v}} 1.3, \mathrm{~K}_{\mathrm{v}} 3.1, \mathrm{~K}_{\mathrm{v}} 7.2, \mathrm{Ca}^{2+}$-activated SK2 and TREK1 conferred photosensitivity on these $\mathrm{K}^{+}$channels (Fortin et al., 2011; Sandoz et al., 2012). These novel light-sensitive channels are highly interesting targets for optical control. For example, $\mathrm{K}_{\mathrm{V}} 7.2$ is a potassium channel underlying the M-current and has also been implicated in epilepsy (Brown and Passmore, 2009), while the calcium-activated SK2 channel modulates excitatory post-synaptic potentials and contributes to long-term potentiation in the hippocampus (Adelman et al., 2011). TREK1 channels are polymodal channels, being sensitive to temperature, pressure, $\mathrm{pH}$ and intracellular signaling (Alloui et al., 2006). Specific photomodulation of TREK1 revealed that they are also activated by $\mathrm{GABA}_{\mathrm{B}}$ signaling in the hippocampus (Sandoz et al., 2012).

$\mathrm{K}^{+}$channels are not the only family of transmembrane proteins that can be targeted with the PTL strategy. We have recently developed a series of light-regulated neuronal nAChRs (LinAChRs) which can be conjugated with photoswitchable agonists or antagonists, allowing for powerful bidirectional control

A
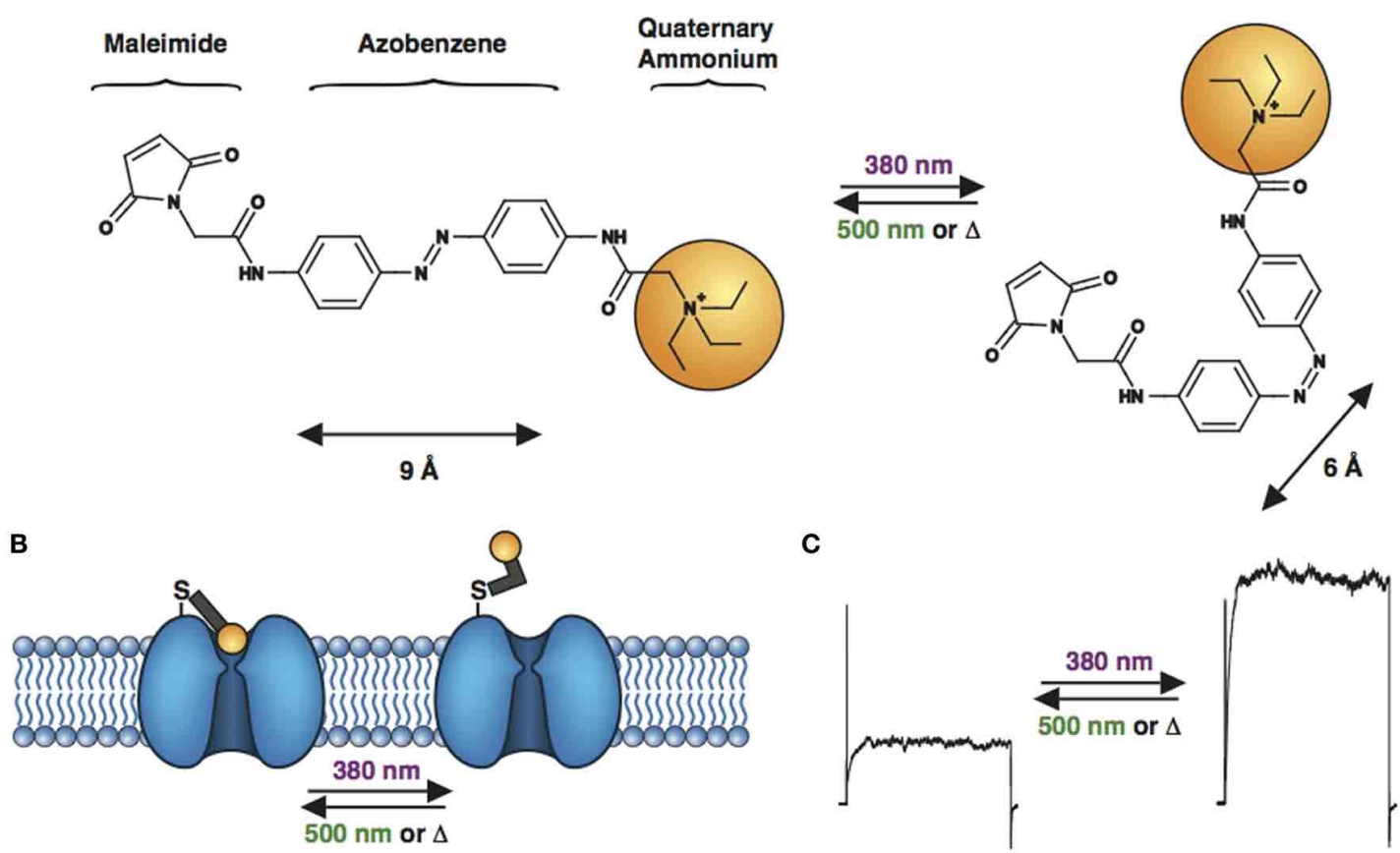

FIGURE 4 | Engineered potassium channels with a photoswitchable tethered ligand (PTL). (A) Chemical structures of trans (left) and cis (right) MAQ (Maleimide-Azobenzene-Quaternary ammonium). The end-to-end distance between the para positions of the azobenzene shortens by $\sim 3 \AA$ upon isomerization from trans to cis. (B) Scheme of a genetically-encoded, photoswitchable $\mathrm{K}^{+}$channel. MAQ is covalently attached on an engineered cysteine located on the extracellular surface of a $\mathrm{K}^{+}$channel. In the extended trans configuration (dark or $500 \mathrm{~nm}$ light), MAQ blocks ion conduction. Photoisomerization to cis with $380 \mathrm{~nm}$ light shortens $\mathrm{MAQ}$ and relieves block. (C) Current through a photoswitchable Kv3.1 channel labeled with MAQ, under both wavelengths of light. 
of receptor activity (Tochitsky et al., 2012). Given the wide variety of $\mathrm{nAChR}$ subtypes present in the brain and the lack of specific pharmacology for them, LinAChRs should prove highly useful in studying the function of nAChRs in the nervous system. Furthermore, controlling specific nAChRs in the brain may help shed light on their role in nicotine addiction and various neurodegenerative and neuropsychiatric disorders. Another major class of channels targeted with PTLs is the glutamate receptor (GluR) family. A series of ionotropic glutamate receptors belonging to the kainate receptor family (iGluR6) could be activated by light after conjugation of a photoswitchable agonist to an engineered mutant cysteine residue (Volgraf et al., 2005; Gorostiza et al., 2007; Numano et al., 2009). The resulting lightactivated glutamate receptors (LiGluRs and HyLighter) enabled the remote control of neuronal electrical activity both in vitro (Szobota et al., 2007) and in vivo in zebrafish larvae (Janovjak et al., 2010; Wyart et al., 2010) and in mice (Caporale et al., 2011).

The success and relative ease of generating novel light-sensitive ion channels demonstrate the power of the PTL approach, as almost any channel or receptor can, in principle, be rendered light-sensitive by combining existing pharmacological and structural information. Synthetic organic chemistry can generate photosensitive variants of existing receptor ligands. Molecular modeling can then identify a region of interest where cysteine scanning mutagenesis would determine the optimal position for PTL attachment. Once a particular channel has been photosensitized, structurally similar relatives can be photosensitized as well, often simply by transposing the cysteine mutation from one subtype to another (Fortin et al., 2011; Tochitsky et al., 2012). A PTL-conjugated receptor can be controlled specifically, with either an agonist or antagonist/pore blocker, with a spatial and temporal precision simply impossible with traditional diffusible ligands. The combination of rational design, specificity and precision makes the PTL approach a very powerful tool for identifying the roles of particular ion channel subtypes in complex neural networks, both in vitro and in vivo.

So far, the designer receptor strategy has mainly been used in vitro, where gene delivery and conjugation of the PTL onto the engineered cysteine mutation are relatively staightforward. In vivo, its use has been restricted to zebrafish larvae where the PTL can be added to the water where fish swim and absorbed through the skin (Janovjak et al., 2010; Wyart et al., 2010) and to the mouse retina where the PTL can be easily injected into the vitreous cavity of the eye (Caporale et al., 2011). Traditional optogenetic tools (e.g., channelrhodopsin) have an advantage over designer receptors in this regard, since the photoswitch retinal is naturally present in cells and does not have to be introduced exogenously. Nonetheless, designer receptors can be used to answer questions that would be hard to address with channelrhodopsin. For example, engineered receptors can reveal a causal relationship between receptor activation in a given cell type and the activity of a neuronal circuit or the induction of a certain behavior. Lightsensitive designer receptors can also be used to investigate the function of receptors with different subunit compositions, or the function of a specific receptor expressed in different cell types. However, before these new optical tools can be generally used in mammals in vivo, a certain number of challenges must be overcome:

Gene delivery: photosensitive ion channels can be overexpressed in neurons and manipulated with light in order to study their function, but it is preferable to maintain the endogenous level of gene expression in order to ensure that the results are physiologically relevant. Such a system can be created via the generation of a knock-in animal, where the endogenous channel is replaced by the cysteine mutant, although this approach is laborious and costly. Alternatively, the cysteine mutant subunit can be expressed in a system where it would need to coassemble with an endogenous wild-type subunit for trafficking to the plasma membrane. This photoswitchable conditional subunit strategy was successfully utilized in vitro for the photosensitive TREK1 two pore $\mathrm{K}^{+}$channel (Sandoz et al., 2012) and should be feasible in vivo for other heteromeric ion channels such as brain nAChRs. Expression of the cysteine-containing subunit can in principle be done in the wild-type background, although the use of a knock-out animal is preferred to maximize the degree of photocontrol. In vivo gene delivery can be done using lentior adeno-associated (AAV) viral vectors, or the in utero electroporation technique (Fenno et al., 2011).

Cell-type specific expression: one method of manipulating genetically defined neuronal subtypes involves the expression of the gene of interest under the control of cell-type specific promoters. Another possibility is to use Cre recombinase-inducible expression systems in conjunction with transgenic animals expressing Cre in specific neuronal populations. Cre recombinase will catalyze the recombination between two loxP sites, resulting in the reversal of the gene's orientation and allowing for the gene's mRNA to be transcribed. High levels of cell type specificity can usually be achieved with this technique (Fenno et al., 2011). Light delivery: since the advent of optogenetics, different hardware setups have been used to deliver light in vitro and in vivo (Fenno et al., 2011). Lasers coupled to optic fibers are most commonly used to deliver light into the brain. The fiber can be placed either in the same brain area as the virus injection or in projection targets.

PTL delivery: one of the biggest challenges of our PTL approach is the delivery of the photoswitch. Because of maleimide's reactivity, delivery has to be done locally into the brain, using a guide cannula for example. The cannula can be chronically implanted into the animal, allowing for the delivery of both the chemical photoswitch and the optical stimulation fiber to the region of interest. Since it covalently tethers to its receptor, the PTL can be applied hours before an experiment, ensuring that the excess non-conjugated PTL will diffuse or be metabolized. Another important factor to consider is the efficiency of conjugation, which depends on the oxidation state of the cysteines. Reducing agents such as DTT or TCEP have been used in vitro to reduce cysteines and increase labeling; it is not clear whether these agents will also be required for in vivo use.

\section{BIOMEDICAL APPLICATIONS}

Gene therapy with optogenetic tools has been proposed as a strategy for restoring vision (Busskamp and Roska, 2011) as well 
as for treating Parkinson's disease or epilepsy through deep brain optical stimulation (Gradinaru et al., 2009). Although current gene therapy trials for CNS diseases have shown good safety, it is not clear how the human immune system will tolerate the high levels of microbial opsin expression required for photosensitizing neurons. In contrast, due to its non-genetic nature, the PCL approach for photosensitizing neurons should provide a readily reversible, safe therapeutic strategy. Here we describe the potential use of PCLs for the treatment of blindness and management of chronic pain.

\section{VISION}

Given that the use of PCLs for clinical applications is limited by the ability to deliver light to a particular tissue or organ, the visual system was selected as an ideal clinical target due to the inherent ease of light delivery to the eye. Restoration of neural light sensitivity is needed to treat several degenerative retinal disorders, such as retinitis pigmentosa and age-related macular degeneration, which are characterized by the progressive loss of rod and cone photoreceptors, eventually leading to complete blindness (Jones et al., 2012). In such end-stage blinding diseases, the photoreceptors are absent but other types of neurons in the retina, including retinal ganglion cells (RGCs), bipolar and amacrine cells remain intact (Figures 5A,B). We decided to test whether treatment of the blind retina with AAQ would confer light sensitivity onto these remaining neurons and whether this engineered light response could drive visually guided behavior in vivo.
To evaluate the effect of the PCL, we selected the $r d 1 / r d 1$ mouse model of end-stage retinitis pigmentosa, in which virtually all photoreceptors die by 3 months after birth (Sancho-Pelluz et al., 2008). Prior to AAQ treatment, no light responses were observed on the multi-electrode array (MEA) (Figure 5C), which records the activity of dozens of RGCs in vitro. After treatment with $\mathrm{AAQ}$, we observed a dramatic increase in RGC activity upon stimulation with $380 \mathrm{~nm}$ light, which could be turned off by subsequent $500 \mathrm{~nm}$ illumination (Figure 5D) (Polosukhina et al., 2012). This pattern of AAQ-mediated light responses was opposite to what we had previously observed in cultured neurons, where $380 \mathrm{~nm}$ light usually decreases neuronal excitability (Figure 2A). By applying pharmacological synaptic blockers, we determined that AAQ photosensitized all remaining retinal cell types, including the inhibitory amacrine cells. After blockade of inhibitory GABAergic and glycinergic inputs, the RGCs increased their activity in $500 \mathrm{~nm}$ light, consistent with previous findings from cultured neurons (Polosukhina et al., 2012). The photocontrol of inhibitory amacrine synaptic drive thus appears to be the major contributor to light-dependent RGC activity after AAQ treatment.

Amazingly, intraocular injection of AAQ could also restore visually guided behaviors in $r d 1$ mice in vivo. After the injection, previously blind mice displayed light aversive locomotory behavior in a turning assay. Additionally, these mice regained a lightdriven pupillary light reflex. Finally, AAQ-injected $r d 1 / r d 1$ mice displayed light-dependent changes in locomotory activity in an open-field assay. The ability of AAQ to restore light perception to

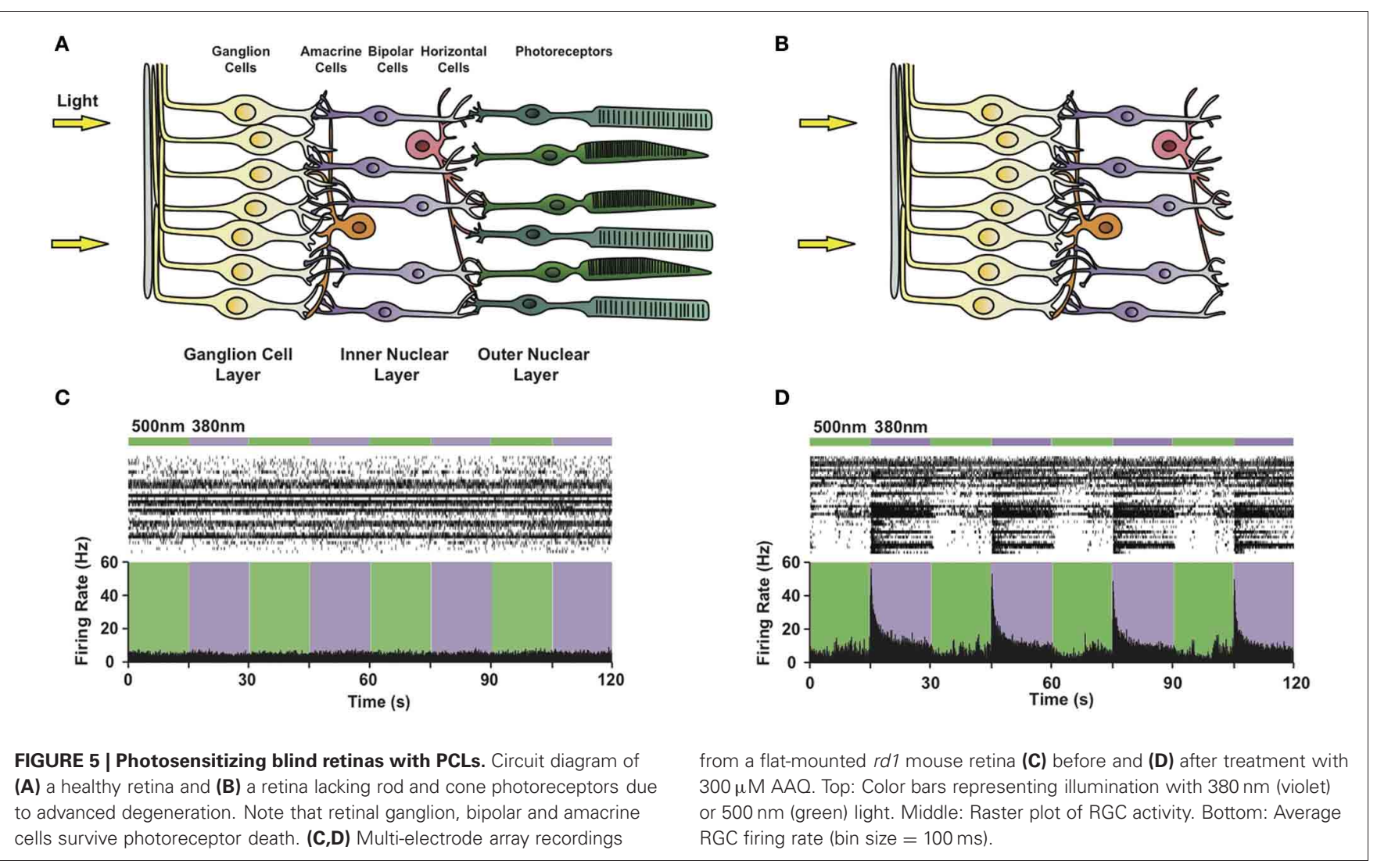


blind mice in vivo makes the PCL approach a promising potential therapy for end-stage retinitis pigmentosa and age-related macular degeneration. Novel $K_{v}$ PCLs such as DENAQ and PHENAQ (Mourot et al., 2011) have a red-shifted absorption spectrum and faster thermal relaxation compared to AAQ. These molecules may be better clinical candidates due to their ability to respond to visible rather than UV light and be controlled with a single wavelength of light. Further chemical synthesis and screening of our existing PCL library should allow us to develop compounds with optimal properties for vision restoration-ones sensitive to dim visible light, safe for intraocular use and producing long-lasting photosensitivity in vivo after a single injection.

\section{CHRONIC PAIN}

Local anesthetics such as lidocaine are potent silencers of neuronal activity and extremely useful clinical drugs for managing acute pain. However, these drugs are not well suited to the treatment of persistent, chronic pain because (1) they lack specificity for motor vs. sensory neurons and also for different sensory modalities (e.g., touch sensation) (2) block duration or intensity cannot be regulated (Roberson et al., 2011). Because QAQ is selective for pain-sensing neurons, it may block nociception without affecting motor axons or other sensations. Moreover, because QAQ blockade can be precisely modulated by changing light wavelength or intensity, it may be possible to photo-titrate the analgesic effect at will.

QAQ could be administered in combination with capsaicin to selectively block TRPV1-containing nociceptors. A similar strategy has been proposed for the membrane-impermeant lidocaine derivative QX-314, which produces long-lasting selective analgesia (Binshtok et al., 2007; Kim et al., 2010). However, because capsaicin activates TRPV1 channels and produces pain, it may be desirable to target nociceptors by other means (Roberson et al., 2011). In pathological pain conditions, nociceptors become hyperactive. Our experiments with QAQ suggest that the basal activity of TRPV1 channels increases in electrically hyperactive neurons (Mourot et al., 2012). If this is the case, capsaicin may not be needed, and QAQ may be self-targeted to the most active nociceptors, i.e., the ones that need to be silenced the most. This finding may explain why QX-314 alone, which is normally unable to cross neuronal membranes, is effective for recovery after spinal

\section{REFERENCES}

Adelman, J. P., Maylie, J., and Sah, P. (2011). Small-conductance Ca2+activated $\mathrm{K}+$ channels: form and function. Physiology 74, 245-269.

Agrawal, S. K., and Fehlings, M. G. (1997). The effect of the sodium channel blocker QX-314 on recovery after acute spinal cord injury. J. Neurotrauma 14, 81-88.

Alloui, A., Zimmermann, K., Mamet, J., Duprat, F., Noël, J., Chemin, J., et al. (2006). TREK-1, a K+ channel involved in polymodal pain perception. EMBO J. 25, 2368-2376.

Arenkiel, B. R., Klein, M. E., Davison, I. G., Katz, L. C., and Ehlers, M. D. (2008). Genetic control of neuronal activity in mice conditionally expressing TRPV1. Nat. Methods 5, 299-302.

Armbruster, B. N., Li, X., Pausch, M. H., Herlitze, S., and Roth, B. L. (2007). Evolving the lock to fit the key to create a family of $\mathrm{G}$ proteincoupled receptors potently activated by an inert ligand. Proc. Natl. Acad. Sci. U.S.A. 104, 5163-5168.

Banghart, M. R. (2009). Light-Gated Potassium Channels for Photocontrol of Neuronal Firing. Ph.D. thesis, University of California Berkeley, Berkeley, CA.

Banghart, M. R., Borges, K., Isacoff, E. Y., Trauner, D., and Kramer, R. H. (2004). Light-activated ion

cord injury (Agrawal and Fehlings, 1997) and in animal models of neuropathic pain (Omana-Zapata et al., 1997).

Photoregulation of pain sensation in vivo requires light delivery to the targeted neuronal tissue. Because the terminal endings of nociceptive neurons are located just below the skin, an external light source could be used after topical application of QAQ. The cornea, which is fully transparent and highly-enriched in sensory fibers, is the ideal peripheral target, as evidenced by the potent optical regulation of touch-evoked responses seen in living rats (Mourot et al., 2012). Red-shifted derivatives of QAQ (Mourot et al., 2011) may be more appropriate for the optical regulation of pain deeper in the skin or in internal structures such as the spinal cord, in combination with implanted fiber-optic systems.

\section{CONCLUSION}

We have developed multiple one-component PCL and twocomponent PTL systems for photosensitizing ion channels naturally present in neurons. Both of these strategies work well in vitro and in vivo. Chemical PCLs render many types of neurons sensitive to light within minutes without requiring exogenous gene expression. They are photosensitive pharmacological agents, the activity of which can be rapidly turned on or off with light. As such, they provide a unique means to quickly and precisely reverse the activity of drugs in cases where simple perfusion would be slow, tricky or impossible (e.g., the patch pipette). They are also promising clinical candidates for treating blindness and pathological pain. In contrast, PTLs are highly sophisticated molecular tools that enable the optical control of a defined ion channel in a targeted cell population. This ability to specifically control a given receptor in a defined neuronal population and monitor changes in behavior due to its activation or inhibition should provide an unprecedented ability to uncover the functional connectivity of the nervous system. Our studies will thus be crucial to the design of novel, targeted drugs for treating neurological and neuropsychiatric disorders.

\section{ACKNOWLEDGMENTS}

We would like to thank Matthew R. Banghart (Harvard Medical School) for extensive discussion and critical feedback on the article. This research was supported by US National Institutes of Health grants MH088484 and PN2 EY018241.

channels for remote control of neuronal firing. Nat. Neurosci. 7, 1381-1386.

Banghart, M. R., Mourot, A., Fortin, D. L., Yao, J. Z., Kramer, R. H., and Trauner, D. (2009). Photochromic blockers of voltage-gated potassium channels. Angew. Chem. Int. Ed. Engl. 48, 9097-9101.

Banghart, M. R., and Trauner, D. (2013). "A 1H NMR assay for quantifying the wavelength sensitivity of azobenzene-based photoswitchable ligands," in Methods in Molecular Biology: Protocols for Chemical Neurobiology, Vol. 995, ed M. R. Banghart (New York, NY: Springer), 107-120.
Bartels, E., Wassermann, N. H. and Erlanger, B. F. (1971). Photochromic activators of the acetylcholine receptor. Proc. Natl. Acad. Sci. U.S.A. 68, 1820-1823.

Beharry, A. A., Sadovski, O., and Woolley, G. A. (2008). Photocontrol of peptide conformation on a timescale of seconds with a conformationally constrained, blue-absorbing, photo-switchable linker. Org. Biomol. Chem. 6, 4323.

Beharry, A. A., Sadovski, O., and Woolley, G. A. (2011). Azobenzene Photoswitching without Ultraviolet Light. J. Am. Chem. Soc. 133, 19684-19687. 
Beharry, A. A., and Woolley, G. A. (2011). Azobenzene photoswitches for biomolecules. Chem. Soc. Rev. 40, 4422.

Binshtok, A. M., Bean, B. P., and Woolf, C. J. (2007). Inhibition of nociceptors by TRPV1-mediated entry of impermeant sodium channel blockers. Nature 449, 607-610.

Bléger, D., Schwarz, J., Brouwer, A. M., and Hecht, S. (2012). o-Fluoroazobenzenes as readily synthesized photoswitches offering nearly quantitative two-way isomerization with visible light. J. Am. Chem. Soc. 134, 20597-20600.

Boyden, E. S., Zhang, F., Bamberg, E., Nagel, G., and Deisseroth, K. (2005). Millisecond-timescale, genetically targeted optical control of neural activity. Nat. Neurosci. 8, 1263-1268.

Brieke, C., Rohrbach, F., Gottschalk, A., Mayer, G., and Heckel, A. (2012). Light-controlled tools. Angew. Chem. Int. Ed. Engl. 51, 8446-8476.

Brown, D. A., and Passmore, G. M. (2009). Neural KCNQ (Kv7) channels. Br. J. Pharmacol. 156, 1185-1195.

Busskamp, V., and Roska, B. (2011). Optogenetic approaches to restoring visual function in retinitis pigmentosa. Curr. Opin. Neurobiol. 21, 942-946.

Caporale, N., Kolstad, K. D., Lee, T., Tochitsky, I., Dalkara, D., Trauner, D., et al. (2011). LiGluR restores visual responses in rodent models of inherited blindness. Mol. Ther. 19, 1212-1219.

Caterina, M. J., Schumacher, M. A., Tominaga, M., Rosen, T. A., Levine, J. D., and Julius, D. (1997). The capsaicin receptor: a heat-activated ion channel in the pain pathway. Nature 389, 816-824.

Cavanaugh, D. J., Chesler, A. T., Jackson, A. C., Sigal, Y. M., Yamanaka, H., Grant, R., et al. (2011). Trpv1 reporter mice reveal highly restricted brain distribution and functional expression in arteriolar smooth muscle cells. J. Neurosci. 31, 5067-5077.

Chambers, J. J., Banghart, M. R., Trauner, D., and Kramer, R. H. (2006). Light-induced depolarization of neurons using a modified shaker $\mathrm{K}+$ channel and a molecular photoswitch. J. Neurophysiol. 96, 2792-2796.

Chi, L., Sadovski, O., and Woolley, G. A. (2006). A blue-green absorbing cross-linker for rapid photoswitching of peptide helix content. Bioconjug. Chem. 17, 670-676.

Choi, K. L., Mossman, C., Aubé, J., and Yellen, G. (1993). The internal quaternary ammonium receptor site of Shaker potassium channels. Neuron 10, 533-541.

Chow, B. Y., Han, X., Dobry, A. S., Qian, X., Chuong, A. S., Li, M., et al. (2010). High-performance genetically targetable optical neural silencing by light-driven proton pumps. Nature 463, 98-102.

Chung, M.-K., Güler, A. D., and Caterina, M. J. (2008). TRPV1 shows dynamic ionic selectivity during agonist stimulation. Nat. Neurosci. 11, 555-564.

Claridge-Chang, A., Roorda, R. D., Vrontou, E., Sjulson, L., Li, H., Hirsh, J., et al. (2009). Writing memories with light-addressable reinforcement circuitry. Cell 139, 405-415.

Coward, P., Wada, H. G., Falk, M. S., Chan, S. D., Meng, F., Akil, H., et al. (1998). Controlling signaling with a specifically designed Gi-coupled receptor. Proc. Natl. Acad. Sci. U.S.A. 95, 352-357.

Deal, W. J., Erlanger, B. F., and Nachmansohn, D. (1969). Photoregulation of biological activity by photochromic reagents. 3. Photoregulation of bioelectricity by acetylcholine receptor inhibitors. Proc. Natl. Acad. Sci. U.S.A. 64, 1230-1234.

Drachman, D., and Strichartz, G. (1991). Potassium channel blockers potentiate impulse inhibition by local anesthetics. Anesthesiology 75, 1051-1061.

Dugué, G. P., Akemann, W., and Knöpfel, T. (2012). A comprehensive concept of optogenetics. Prog. Brain Res. 196, 1-28.

Ellis-Davies, G. C. R. (2007). Caged compounds: photorelease technology for control of cellular chemistry and physiology. Nat. Methods 4, 619-628.

Fehrentz, T. (2012). Design and Characterization of Photochromic Ligands for Voltage-gated ion Channels. Ph.D. thesis, LudwigMaximilians-Universität, Munich.

Fehrentz, T., Kuttruff, C. A., Huber, F. M. E., Kienzler, M. A., Mayer, P., and Trauner, D. (2012). Exploring the pharmacology and action spectra of photochromic openchannel blockers. Chembiochem 13 , 1746-1749.

Fehrentz, T., Schönberger, M., and Trauner, D. (2011). Optochemical Genetics. Angew. Chem. Int. Ed. Engl. 50, 12156-12182.

Fenno, L., Yizhar, O., and Deisseroth, K. (2011). The development and application of optogenetics. Аnпи. Rev. Neurosci. 34, 389-412.
Fortin, D. L., Banghart, M. R., Dunn, T. W., Borges, K., Wagenaar, D A., Gaudry, Q., et al. (2008). Photochemical control of endogenous ion channels and cellular excitability. Nat. Methods 5, 331-338.

Fortin, D. L., Dunn, T. W., Fedorchak, A., Allen, D., Montpetit, R., Banghart, M. R., et al. (2011). Optogenetic photochemical control of designer $\mathrm{K}+$ channels in mammalian neurons. J. Neurophysiol. 106, 488-496.

Garcia-Amorós, J., Díaz-Lobo, M., Nonell, S., and Velasco, D. (2012) Fastest thermal isomerization of an azobenzene for nanosecond photoswitching applications under physiological conditions. Angew. Chem. Int. Ed. Engl. 51, 12820-12823.

Goeldner, M., and Givens, R. (2005). Dynamic Studies in Biology. Weinheim: Wiley-VCH.

Gorostiza, P., and Isacoff, E. Y. (2008) Optical switches for remote and noninvasive control of cell signaling. Science 322, 395-399.

Gorostiza, P., Volgraf, M., Numano, R., Szobota, S., Trauner, D., and Isacoff, E. Y. (2007). Mechanisms of photoswitch conjugation and light activation of an ionotropic glutamate receptor. Proc. Natl. Acad. Sci. U.S.A. 104, 10865-10870.

Gradinaru, V., Mogri, M., Thompson, K. R., Henderson, J. M., and Deisseroth, K. (2009). Optical deconstruction of parkinsonian neural circuitry. Science 324 354-359.

Hille, B. (2001). Ion Channels of Excitable Membranes, 3rd Edn. Sunderland, MA: Sinauer Associates Inc. 2001.

Janovjak, H., Szobota, S., Wyart, C., Trauner, D., and Isacoff, E. Y. (2010). A light-gated, potassiumselective glutamate receptor for the optical inhibition of neuronal firing. Nat. Neurosci. 13, 1027-1032.

Jones, B. W., Kondo, M., Terasaki, H., Lin, Y., McCall, M., and Marc, R. E. (2012). Retinal remodeling. Jpn. J. Ophthalmol. 56, 289-306.

Khakh, B. S., Bao, X. R., Labarca, C., and Lester, H. A. (1999). Neuronal P2X transmitter-gated cation channels change their ion selectivity in seconds. Nat. Neurosci. 2, 322-330.

Khakh, B. S., and North, R. A. (2006). P2X receptors as cell-surface ATP sensors in health and disease. Nature 442, 527-532.

Kim, H. Y., Kim, K., Li, H. Y., Chung, G., Park, C.-K., Kim, J. S., et al. (2010). Selectively targeting pain in the trigeminal system. Pain 150, 29-40.

Kole, M. H. P., and Stuart, G. J. (2012). Signal processing in the axon initial segment. Neuron 73, 235-247.

Kramer, R. H., Fortin, D. L., and Trauner, D. (2009). New photochemical tools for controlling neuronal activity. Curr. Opin. Neurobiol. 19, 544-552.

Krouse, M. E., Lester, H. A. Wassermann, N. H., and Erlanger, B. F. (1985). Rates and equilibria for a photoisomerizable antagonist at the acetylcholine receptor of Electrophorus electroplaques. J. Gen. Physiol. 86, 235-256.

Lester, H. A., Krouse, M. E., Nass, M. M., Wassermann, N. H., and Erlanger, B. F. (1979). Light-activated drug confirms a mechanism of ion channel blockade. Nature 280, 509-510.

Lima, S. Q., and Miesenbock, G. (2005). Remote control of behavior through genetically targeted photostimulation of neurons. Cell 121, 141-152.

Magee, J. C. (1997). A synaptically controlled, associative signal for hebbian plasticity in hippocampal neurons. Science 275, 209-213.

Magee, J. C., and Johnston, D. (2005). Plasticity of dendritic function. Curr. Opin. Neurobiol. 15, 334-342.

Magnus, C. J., Lee, P. H., Atasoy, D., Su, H. H., Looger, L. L., and Sternson, S. M. (2011). Chemical and genetic engineering of selective ion channel-ligand interactions. Science 333, 1292-1296.

Markram, H. (1997). Regulation of synaptic efficacy by coincidence of postsynaptic APs and EPSPs. Science 275, 213-215.

Meyers, J. R., MacDonald, R. B., Duggan, A., Lenzi, D., Standaert, D. G., Corwin, J. T., et al. (2003). Lighting up the senses: FM1-43 loading of sensory cells through nonselective ion channels. J. Neurosci. 23, 4054-4065.

Miesenbock, G. (2011). Optogenetic control of cells and circuits. Annu. Rev. Cell Dev. Biol. 27, 731-758.

Möglich, A., and Moffat, K. (2010). Engineered photoreceptors as novel optogenetic tools. Photochem. Photobiol. Sci. 9, 1286.

Mourot, A., Fehrentz, T., and Kramer, R. H. (2013). "Photochromic potassium channel blockers: design and electrophysiological characterization," in Methods in Molecular Biology: Protocols for Chemical Neurobiology, Vol. 995, ed M. R. Banghart (New York, NY: Springer), 89-105. 
Mourot, A., Fehrentz, T., Le Feuvre, Y., Smith, C. M., Herold, C., Dalkara, D., et al. (2012). Rapid optical control of nociception with an ionchannel photoswitch. Nat. Methods 9, 396-402.

Mourot, A., Kienzler, M. A., Banghart, M. R., Fehrentz, T., Huber, F. M. E., Stein, M., et al. (2011). Tuning photochromic ion channel blockers. ACS Chem. Neurosci. 2, 536-543.

Numano, R., Szobota, S., Lau, A. Y., Gorostiza, P., Volgraf, M., Roux, B., et al. (2009). Nanosculpting reversed wavelength sensitivity into a photoswitchable iGluR. Proc. Natl. Acad. Sci. U.S.A. 106, 6814-6819.

Omana-Zapata, I., Khabbaz, M. A., Hunter, J. C., and Bley, K. R. (1997). QX-314 inhibits ectopic nerve activity associated with neuropathic pain. Brain Res. 771, 228-237.

Pathak, G. P., Vrana, J. D., and Tucker, C. L. (2012). Optogenetic control of cell function using engineered photoreceptors. Biol. Cell. 105, 59-72.

Pham, E., Mills, E., and Truong, K. (2011). A synthetic photoactivated protein to generate local or global Ca2+ signals. Chem. Biol. 18, 880-890.

Polosukhina, A., Litt, J., Tochitsky, I., Nemargut, J., Sychev, Y., De Kouchkovsky, I., et al. (2012). Photochemical restoration of visual responses in blind mice. Neuron 75 , 271-282.

Rau, H. (1973). Spectroscopic properties of organic azo compounds. Angew. Chem. Int. Ed. Engl. 12, 224-235.

Roberson, D. P., Binshtok, A. M., Blasl, F., Bean, B. P., and Woolf, C. J. (2011). Targeting of sodium channel blockers into nociceptors to produce long-duration analgesia: a systematic study and review. $\mathrm{Br}$. J. Pharmacol. 164, 48-58.

Rogan, S. C., and Roth, B. L. (2011). Remote control of neuronal signaling. Pharmacol. Rev. 63, 291-315.

Sadovski, O., Beharry, A. A., Zhang, F., and Woolley, G. A. (2009). Spectral tuning of azobenzene photoswitches for biological applications. Angew. Chem. Int. Ed. Engl. 48, 1484-1486.
Sancho-Pelluz, J., Arango-Gonzalez, B., Kustermann, S., Romero, F. J., Veen, T., Zrenner, E., et al. (2008). Photoreceptor cell death mechanisms in inherited retinal degeneration. Mol. Neurobiol. 38, 253-269.

Sandoz, G., Levitz, J., Kramer, R. H., and Isacoff, E. Y. (2012). Optical control of endogenous proteins with a photoswitchable conditional subunit reveals a role for TREK1 in GABAB signaling. Neuron 74, 1005-1014.

Scholz, A. A. (2002). Mechanisms of (local) anaesthetics on voltage-gated sodium and other ion channels. $\mathrm{Br}$. J. Anaesth. 89, 52-61.

Smirnov, S., Paalasmaa, P., Uusisaari, M., Voipio, J., and Kaila, K. (1999). Pharmacological isolation of the synaptic and nonsynaptic components of the GABA-mediated biphasic response in rat CA1 hippocampal pyramidal cells. J. Neurosci. 19, 9252-9260.

Stawski, P., Sumser, M., and Trauner, D. (2012). A photochromic agonist of AMPA receptors. Angew. Chem. Int. Ed. Engl. 51, 5748-5751.

Stein, M., Middendorp, S. J., Carta, V., Pejo, E., Raines, D. E., Forman, S. A., et al. (2012). Azo-propofols: photochromic potentiators of GABAA receptors. Angew. Chem. Int. Ed. Engl. 51, 10500-10504.

Strichartz, G. R. (1973). The inhibition of sodium currents in myelinated nerve by quaternary derivatives of lidocaine. J. Gen. Physiol. 62, 37-57.

Szobota, S., Gorostiza, P., Del Bene, F., Wyart, C., Fortin, D. L., Kolstad, K. D., et al. (2007). Remote control of neuronal activity with a lightgated glutamate receptor. Neuron 54, 535-545.

Taglialatela, M., Vandongen, A. M., Drewe, J. A., Joho, R. H., Brown, A. M., and Kirsch, G. E. (1991). Patterns of internal and external tetraethylammonium block in four homologous $\mathrm{K}+$ channels. Mol. Pharmacol. 40, 299-307.

Tochitsky, I., Banghart, M. R., Mourot, A., Yao, J. Z., Gaub, B., Kramer, R. H., et al. (2012). Optochemical control of genetically engineered neuronal nicotinic acetylcholine receptors. Nat. Chem. 4, 105-111.

Valera, S., Hussy, N., Evans, R. J., Adami, N., North, R. A., Surprenant, A., et al. (1994). A new class of ligand-gated ion channel defined by $\mathrm{P} 2 \mathrm{x}$ receptor for extracellular ATP. Nature 371, 516-519.

Vaziri, A., and Emiliani, V. (2012). Reshaping the optical dimension in optogenetics. Curr. Opin. Neurobiol. 22, 128-137.

Virginio, C., MacKenzie, A. Rassendren, F. A., North, R. A., and Surprenant, A. (1999). Pore dilation of neuronal P2X receptor channels. Nat. Neurosci. 2, 315-321.

Volgraf, M., Gorostiza, P., Numano, R., Kramer, R. H., Isacoff, E. Y., and Trauner, D. (2005). Allosteric control of an ionotropic glutamate receptor with an optical switch. Nat. Chem. Biol. 2, 47-52.

Volgraf, M., Gorostiza, P., Szobota, S., Helix, M. R., Isacoff, E. Y., and Trauner, D. (2007). Reversibly caged glutamate: a photochromic agonist of ionotropic glutamate receptors. J. Am. Chem. Soc. 129, 260-261.

Wang, G. K., Quan, C., Vladimirov M., Mok, W. M., and Thalhammer, J. G. (1995). Quaternary ammonium derivative of lidocaine as a long-acting local anesthetic. Anesthesiology 83, 1293-1301.

Warther, D., Gug, S., Specht, A., Bolze, F., Nicoud, J. F., Mourot, A., et al. (2010). Two-photon uncaging: new prospects in neuroscience and cellular biology. Bioorg. Med. Chem. 18, 7753-7758.

Wilent, W. B., and Contreras, D. (2005) Dynamics of excitation and inhibition underlying stimulus selectivity in rat somatosensory cortex. Nat. Neurosci. 8, 1364-1370.

Wulff, P., and Arenkiel, B. R. (2011) Chemical genetics: receptor-ligand pairs for rapid manipulation of neuronal activity. Curr. Opin. Neurobiol. 22, 1-7.

Wulff, P., Goetz, T., Leppä, E., Linden, A.-M., Renzi, M., Swinny, J. D., et al (2007). From synapse to behavior: rapid modulation of defined neuronal types with engineered
GABAA receptors. Nat. Neurosci. 10, 923-929.

Wyart, C., Del Bene, F., Warp, E., Scott, E. K., Trauner, D., Baier, H., et al. (2010). Optogenetic dissection of a behavioural module in the vertebrate spinal cord. Nature 461, 407-410.

Yizhar, O., Fenno, L. E., Davidson, T. J., Mogri, M., and Deisseroth, K. (2011). Optogenetics in neural systems. Neuron 71, 9-34.

Yue, L., Pawlowski, M., Dellal, S. S., Xie, A., Feng, F., Otis, T. S., et al. (2012). Robust photoregulation of GABAA receptors by allosteric modulation with a propofol analogue. Nat. Commun. 3, 1095.

Zemelman, B. V., Nesnas, N., Lee, G. A., and Miesenbock, G. (2003). Photochemical gating of heterologous ion channels: remote control over genetically designated populations of neurons. Proc. Natl. Acad. Sci. U.S.A. 100, 1352-1357.

Zhang, F., Wang, L.-P., Brauner, M., Liewald, J. F., Kay, K., Watzke, N., et al. (2007). Multimodal fast optical interrogation of neural circuitry. Nature 446, 633-639.

Conflict of Interest Statement: The authors declare that the research was conducted in the absence of any commercial or financial relationships that could be construed as a potential conflict of interest.

Received: 23 January 2013; paper pending published: 13 February 2013; accepted: 06 March 2013; published online: 21 March 2013.

Citation: Mourot A, Tochitsky I and Kramer RH (2013) Light at the end of the channel: optical manipulation of intrinsic neuronal excitability with chemical photoswitches. Front. Mol. Neurosci. 6:5. doi: 10.3389/fnmol.2013.00005

Copyright (c) 2013 Mourot, Tochitsky and Kramer. This is an open-access article distributed under the terms of the Creative Commons Attribution License, which permits use, distribution and reproduction in other forums, provided the original authors and source are credited and subject to any copyright notices concerning any third-party graphics etc. 